\title{
ABOUT
}

Welcome to the International Scientific and Practical Conference "Law and the Information Society: Digital Approach" (LISID-2020), which took place on November 5-6, 2020 in a Zoom format in the Volgograd Institute of Management a branch of the Russian Academy of National Economy and State Services under the President of the Russian Federation, Volgograd, Russia.

LISID-2020 is a good opportunity to share experience, modern knowledge and achievements in the field of legal aspects of the digital society, in the context of the evolution of intellectual property rights in the information society; changing approaches to legal technology in the digital space; law and digital medicine, digital education; socio-cultural studies of information and communication technologies in a digital society, economic models and information society management; security problems in the information society; digital environment, information communication systems and media culture in the information age.

The purpose of the conference is to discuss and forecast future trends in the development of the information society and its legal aspects, exchange advanced knowledge in the field of digital governance and law.

106 manuscripts were submitted to LISID-2020. And 41 manuscripts were approved and accepted by our reviewers. By submitting a document to LISID-2020, the authors agree with the review process and understand the importance of the review process for their work. The manuscripts were reviewed by qualified experts in the fields selected by the organizing committee of the conference, who provided detailed comments. All papers were peer-reviewed using a double-blind review process: authors list their names and affiliations in the manuscript for reviewers, but the reviewers did not know each other's identities and whether the authors received information about who reviewed their manuscript. The organizing committee organized the sessions so that the participants could get the maximum benefit.

We express our deepest gratitude to the organizers, conference participants, LISID 2020 committees and reviewers for their hard work. Without their participation, it would have been impossible for us to successfully hold LISID-2020 and ensure the high quality of conference materials.

We also want to express our gratitude to the large number of authors who submitted and presented the results of their research at the conference.

Special thanks go to the SHS Web of Conferences journal editors and team. We also look forward to furthering fruitful cooperation.

\section{LISID-2020 Organizing Committee}

\section{Guest editor(s)}

Cindori Sonja, Associate Professor, Faculty of Law University of Zagreb, Croatia Mostafa Aimoatassembellah Mostafa Mohamed, Deputy Dean of the Faculty of Law, Doctor of Laws, University of El Mansour, Egypt 
Malushko E.Yu., Candidate of Pedagogical Sciences, Associate Professor, Deputy Director for Informatization of the Institute of Philology and intercultural communication of the Volgograd State University

Deryugina T.V., Doctor of Law, Professor of the Department of Civil and Labor Law, Civil Procedure of the Federal State Educational Institution of Higher Education "Moscow University of the Ministry of Internal Affairs of the Russian Federation named after V.Ya. Kikotya"

Mokhov A.A., Doctor of Law, Professor, Head of the Department of Medical Law, Moscow State Law University named after O.E. Kutafina (Moscow State Law Academy) 